\title{
Right place, right time? Making crime pattern theory time-specific
}

\author{
Sabine E. M. van Sleeuwen ${ }^{1,2^{*}}$, Stijn Ruiter ${ }^{1,2}$ and Wouter Steenbeek ${ }^{2}$
}

\begin{abstract}
Objectives: Crime pattern theory and the related empirical research have remained rather a-temporal, as if the timing of routine activities and crime plays no role. Building on previous geography of crime research, we extend crime pattern theory and propose that an offender's spatial knowledge acquired during daily routine activities is not equally applicable to all times of day.

Methods: We put this extended theory to a first empirical test by applying a discrete spatial choice model to detailed information from the Netherlands on 71 offences committed by 30 offenders collected through a unique online survey instrument. The offenders reported on their most important activity nodes and offence locations over the past year, as well as the specific times they regularly visited these locations.

Results: The results show that almost $40 \%$ of the offences are committed within the neighbourhoods of offenders' activity nodes, increasing to $85 \%$ when including first-, second- and third-order neighbourhoods. Though not statistically significant in our small sample, the results further suggest that offenders are more likely to commit crime in neighbourhoods they have regularly visited at the same time of day than in neighbourhoods they have regularly visited at different times of day.
\end{abstract}

Conclusion: Our extension of crime pattern theory is only tentatively supported. We argue for replication research with larger samples before any firm conclusions are warranted.

Keywords: Crime pattern theory, Routine activities, Time of day, Time-specific Activity Space (TAS) survey, Discrete spatial choice

\section{Introduction}

\section{Background}

Why do crimes occur both where and when they do? Environmental criminologists have been studying these questions for decades (Wortley and Townsley 2017). Much research has focused on the spatial clustering of crime (e.g., Chainey and Ratcliffe 2013; Eck et al. 2005; Sherman et al. 1989), on patterns of (near) repeat victimization (e.g., Bowers and Johnson 2005; Farrell et al. 1995; Morgan 2001) and on seasonal variations in crime

\footnotetext{
*Correspondence: s.e.m.vansleeuwen@uu.nl; svansleeuwen@nscr.n

${ }^{1}$ Department of Sociology, Utrecht University, Padualaan 14, 3584 $\mathrm{CH}$ Utrecht, The Netherlands

Full list of author information is available at the end of the article
}

(e.g., Andresen and Malleson 2013; Ceccato 2005; Linning et al. 2017). Since the 1970s, a number of key environmental criminological theories have been developed for understanding why such spatio-temporal crime patterns exist. Instead of individuals' motivations to engage in crime, these theories start from the spatio-temporal organization of people's activities and opportunities for crime. Cohen and Felson (1979) defined the crime event as the convergence in space and time of a motivated offender with a suitable target in the absence of capable guardians.

Where such convergences are most likely to occur is best understood using the geometry of crime in crime pattern theory (Brantingham et al. 2017; Brantingham and Brantingham 1981, 1993). According to this theory, 


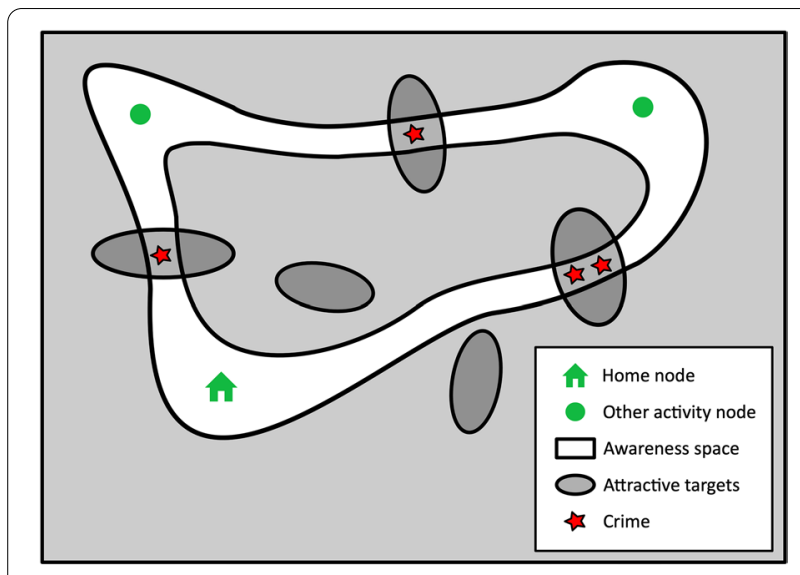

Fig. 1 Predicted crime locations according to crime pattern theory (adapted from Brantingham and Brantingham (1981, p. 42)) literature on crime location choice, see Ruiter 2017). Research showed that offenders commit crimes near their current and former residential homes (e.g., Baudains et al. 2013; Bernasco and Kooistra 2010; Johnson and Summers 2015), as well as those of close family members (e.g., Menting 2018; Rossmo et al. 2014) and friends (e.g., Wiles and Costello 2000). Offenders are also likely to return to previously targeted areas (e.g., Bernasco et al. 2015; Van Sleeuwen et al. 2018) and they commit offences close to other routine activity nodes such as their schools, workplaces and locations for leisure activity (Menting et al. 2020).

Although the core of crime pattern theory explains spatial patterns in crime, it also addresses temporal crime patterns by acknowledging that target attractiveness can be time-varying. A place might be attractive for crime during the day but unattractive at night. For
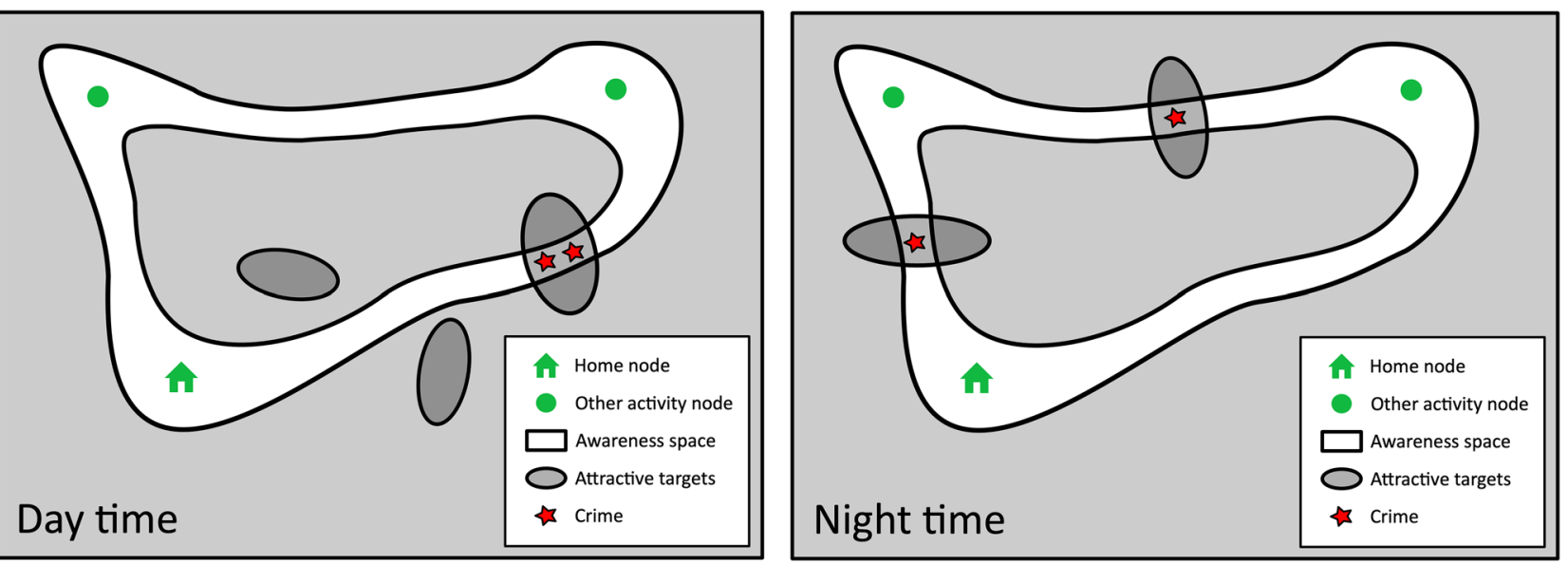

Fig. 2 Attractive targets are present at different locations during the day (left) and during the night (right), impacting the predicted crime locations at different times of day

everyone-including offenders-develops an individual awareness space that consists of their major routine activity nodes such as home, school, workplaces, and leisure activity locations (i.e. their activity space), the travel paths that connect them and everything within the visual range of the offender. When visiting these activity nodes, offenders acquire knowledge of their spatial environment (Brantingham and Brantingham 1981). As depicted in Fig. 1, the theory posits that offenders are most likely to commit crime (the red stars) at those locations where their individual awareness space (in white) intersects with the spatial distribution of suitable targets (the dark ellipses).

Over the past decades, a considerable body of knowledge has been developed about the locations where offenders tend to commit crime (for a comprehensive example, homes are often occupied in the evening and night but vacant during office hours, whereas this pattern is reversed for most businesses and facilities. Figure 2 depicts this by decomposing the locations of targets from Fig. 1 into time-varying target attractiveness, showing that the same place can be attractive for an offender during the day but not so much during the night. Hence, offenders are only expected to commit crime at those places when targets are attractive. ${ }^{1}$ Brantingham et al. (2017) recently provided an example of this when they

\footnotetext{
${ }^{1}$ For clarity reasons, we only show the presence or absence of attractive targets (the grey circles). In reality, target attractiveness might vary more gradually over time.
} 
stated that "the argument for complete randomness of targets and victims is no longer plausible" (p. 98).

\section{The present study}

We argue that Fig. 2 only tells half of the story. Building on previous geography of crime research, the aim of this article is twofold. First, expanding upon previous theoretical arguments made by others (see e.g., Curtis-Ham et al. 2020; Johnson et al. 2007; Van Sleeuwen et al. 2018), we argue how crime pattern theory needs to be extended to better understand both where and when crimes are committed. Specifically, we argue that the theory needs to include time-varying applicability of spatial knowledge. Although time-varying target attractiveness is acknowledged (see Fig. 2), crime pattern theory has so far ignored that specific knowledge of one's spatial environment acquired during daily routines might only be applicable to specific times. All tests of the theory thus far have implicitly assumed a-temporal and time-stable awareness spaces, which suggests that offenders would be equally aware of criminal opportunities at different times of the day irrespective of when they actually visit the places during their routine activities. From this assumption follows that offenders would commit offences in all possible places within their awareness spaces at any time and day. We question this assumption and posit that the spatial knowledge offenders acquire during their daily routine activities is often only applicable at certain times of day (also see Van Sleeuwen et al. 2018).

Van Sleeuwen et al. (2018) already argued that repeat offenders would especially return to previously targeted areas at the same time of day, while Johnson et al. (2007) applied the idea of similarity in time of day to the specific case of (near) repeat burglary events. In the present study, we generalize these claims to all offenders and other activity nodes by reconceptualising the concept of awareness space itself. Awareness spaces clearly comprise all kind of activity nodes; not only prior crime locations. And although Curtis-Ham et al. (2020) mention the similarity of prior activity timing as one of the 'relevance' factors in their theoretical framework for estimating crime location choice based on awareness space, they do not specify the underlying mechanism regarding the temporal applicability of spatial knowledge. Our first contribution is thus theoretical: the applicability of the spatial knowledge offenders acquire during their daily routine activities needs to be conceptualized as time-varying in crime pattern theory. We argue for this extension of the theory in order to provide a better explanation for why crimes are committed not only in certain places, but also at certain times.

Second, as a first empirical test of our extended theory, we designed an online survey in which we examined the time-specificity of offender activity spaces in more detail. Most empirical research on crime patterns uses police data, which generally contain very limited information on the activity spaces of offenders. Often only the home and offence location are known (Ruiter 2017). In addition, the one study that investigated other activity nodes such as schools, workplaces and leisure activities (Menting et al. 2020), did not measure at what times of day these places were visited nor the timing of the offences. Lastly, the few ethnographic studies that investigated temporal crime patterns in relation to a variety of different activity nodes were all based on qualitative research designs that did not systematically record an extensive set of routine activity nodes for all offenders that were interviewed (e.g., Cromwell et al. 1991; Rengert and Wasilchick 2000). In the present study, we measured not only the offenders' most important activity nodes and offence locations in the previous year, but also recorded the specific times they regularly visited these activity nodes. This allows for a first test of hypotheses derived from our extended crime pattern theory about time-varying applicability of spatial knowledge using discrete spatial choice models.

\section{Extending crime pattern theory with time-varying applicability of spatial knowledge}

Crime pattern theory acknowledges that some characteristics of places that affect their crime attractiveness are time-varying (e.g., home occupancy in residential neighbourhoods, or the number of cars parked on a parking lot), while other features are relatively time-stable (e.g., the presence of locks and escape routes). As offenders go about their daily routines, they acquire important information about both these time-varying and time-stable features surrounding their routinely visited locations. This information will then be used in their criminal decision-making (see Fig. 2).

However, crime pattern theory has not been explicit about the degree in which offenders' acquired knowledge of their (partly time-varying and partly time-stable) spatial environment is actually applicable at different times (also see Van Sleeuwen et al. 2018). By definition, the acquired knowledge of time-constant characteristics will apply regardless of the specific time. But the same cannot be said of time-varying characteristics: knowledge of time-varying features might only apply to specific times of day (i.e., the same times of day at which this knowledge was acquired). Of course, using simple heuristics, part of the knowledge that relates to time-varying features might also be generalizable to other times of day, and the offender may act accordingly. Even if offenders might have specific routine activity nodes they exclusively visit during the day, such as workplaces or shopping malls, they could still make good estimations about 

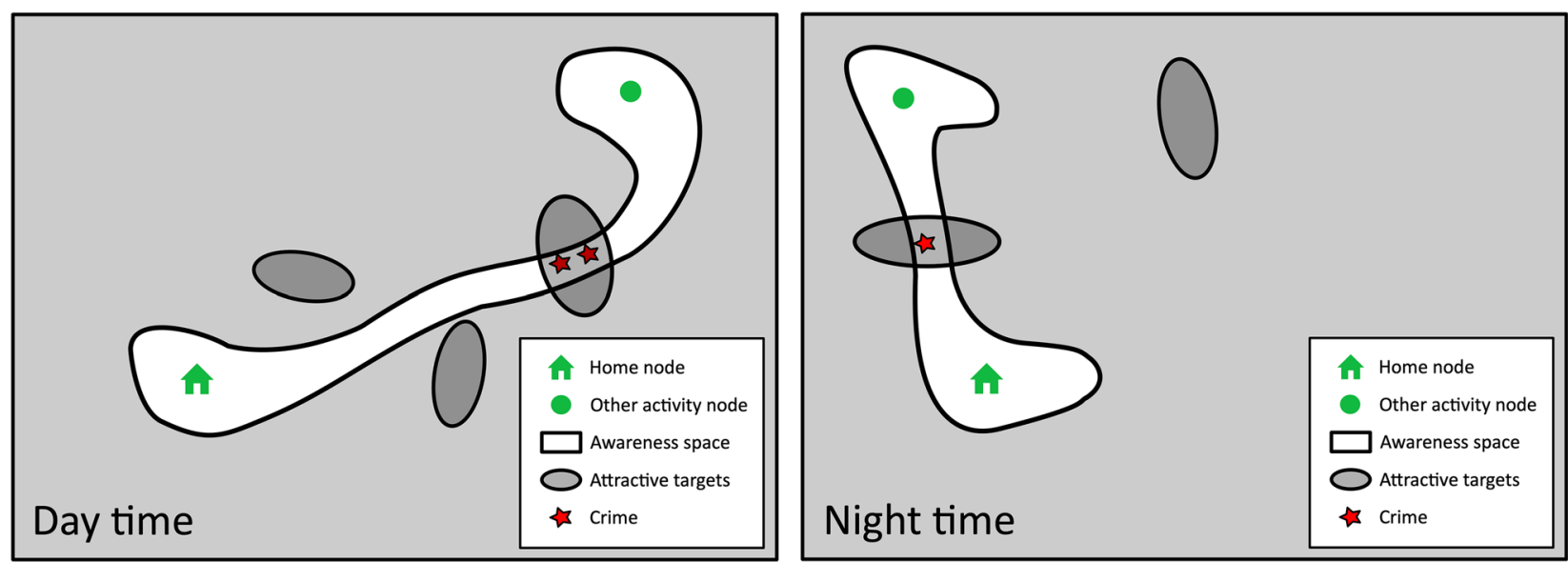

Fig. 3 Extended crime pattern theory, illustrating the applicability of spatial knowledge during the day (left) and during the night (right)

what the situation would be like at night. For example, based on the regular opening and closing hours of supermarkets, offenders who only visit those places during daytime shopping can still make reasonably good inferences about not many people being at that location after $9 \mathrm{pm}$ because the shop is then closed.

Nevertheless, the knowledge that people gain about a certain area at a certain time of day by directly observing it during their routine visits, is more accurate and therefore better applicable to what the situation would look like around that time of day than a generalization based on heuristics. For example, the area around the supermarket might actually be quite busy after $9 \mathrm{pm}$ for a completely different reason. Hence, the acquired knowledge of a certain activity node will be more applicable when the node was previously visited at a similar time. Let's revisit the crime pattern theory diagrams and imagine that it shows the awareness space of an offender who regularly visits three activity nodes: his home, his work location, and his favourite bar in a drinking area. As the offender only visits the drinking area late at night, he develops spatial awareness that mainly applies to the nighttime setting and it is unrealistic to assume that the knowledge about the area is equally applicable to the daytime setting. At night, his spatial knowledge thus best applies to the area where the bar is located. In the daytime, the offender is expected to have more accurate knowledge about suitable targets in the area he usually visits during office hours, because he works there. At both times, the offender will be aware of what the situation is like in his home area. As depicted in Fig. 3, we thus argue for time-varying applicability of spatial knowledge: the awareness space itself (in white) differs between daytime and nighttime, and not only the locations of attractive targets as per Fig. 2.
Although Van Sleeuwen et al. (2018) also argued for time-specific applicability of spatial knowledge, our argument expands upon theirs. Van Sleeuwen et al. (2018) argued that offenders develop time-specific knowledge of crime locations and offenders would therefore commit their repeat offences in the same areas at similar times as the prior offences. In the present paper, we generalize this idea and reconceptualise the awareness space concept itself. We posit that the applicability of spatial knowledge about the entire awareness space is time-specific, not only for previous crime locations. This implies that awareness spaces are not merely spatial, as suggested by Fig. 1, but in fact temporally varying due to the fact that people visit routine activity nodes at certain times of day and thus acquire spatial knowledge that is best reflective of those times. This implies that knowledge of suitable targets in certain areas would also be most applicable at the times of day these areas were visited.

Of course, offenders also acquire knowledge about time-stable features of the environment and for many time-varying features often simple heuristics suffice. For example, by knowing the opening hours of businesses and facilities one can generally estimate reasonably well when certain areas will be crowded with people and when they go quiet. For this reason, we expect that even though the offender's knowledge about the crime attractiveness of an area he only visits during the day might be less applicable to that area at night (or vice versa), his knowledge about that particular area is still somewhat applicable to that area. The offender thus has some knowledge of the area, certainly more than that of any other area he does not routinely visit. Routinely visiting an area at a specific time of day will thus provide spatial knowledge about the area that is best applicable to situations at that specific time, and less-but still somewhat-predictive for situations at 
different times. Based on our extension of crime pattern theory to understand both the spatial and temporal patterns in crime, we derive a first set of testable hypotheses about where offenders are expected to commit offences at specific times of day:

Hypothesis 1 Offenders are more likely to commit crime in areas they have regularly visited at the same time of day than in areas they have regularly visited at different times of day.

Hypothesis 2 Offenders are more likely to commit crime in areas they have regularly visited at different times of day than in areas that are outside their activity space.

\section{Data and method}

In order to examine the time-varying applicability of spatial knowledge in more detail and test our hypotheses, we designed the Time-specific Activity Space (TAS) survey. In this online survey, a sample of offenders reported extensively on the locations of the most important activity nodes they had regularly visited the year prior to the survey and at what times of day and days of week they had visited these nodes, as well as where and when they had committed offences. In the remainder of this section, we discuss the design of the study and the sampling procedure, the contents of the questionnaire, and how we operationalized our measures as well as the method used for testing our hypotheses.

\section{Study design and sampling procedure}

After obtaining permission of the Ministry of Justice and Security and Dutch National Police for our study design and a positive advice from the Ethics Committee for Legal and Criminological Research of the Vrije Universiteit Amsterdam, data on suspects from the Dutch police regions The Hague and North-Holland for the year 2017 were obtained. Although information about the final conviction rate for this specific group was not available in the police data, in general, more than $90 \%$ of police suspects are found guilty at a later stage (Blom et al. 2005). For inclusion in our sample, a suspect needed to (1) have at least one recorded offence in 2017 that was filed to the public prosecutor, (2) be 18 years or older at the time of the sample selection, and (3) have a valid home address in the Netherlands for sending the invitation letter. Due to a stricter interpretation of the Dutch police data law, the original suspect dataset obtained from the police only included relatively minor offences that the police did not need a 72-h investigation for (such as vehicle theft and shoplifting). Therefore, only offenders with less serious offences and shorter offence histories were available for possible inclusion in our study. Of the 4102 suspects that met criteria (1) and (2), 3786 (92.3\%) could be matched with Dutch information system on residential addresses (Basisregistratie Personen; BRP) to obtain a valid home address.

Following the same study design as used by Menting et al. (2020), respondents were approached by sending them an initial invitation letter, which contained a link to our project's website and a unique login token for accessing the online survey. All non-respondents were sent a reminder letter after 1.5 weeks. At the beginning of the survey, respondents were presented a detailed information page about the research project, the contents of the questionnaire and a privacy statement. ${ }^{2}$ The survey could only be started after digitally signing the informed consent form. After completing the full survey, respondents were sent a gift card of 25 euro. The invitation letters were sent in several batches from May to July 2019. When the survey was taken offline at the end of August 2019 , a total of 501 respondents had started with the survey (42 letters were returned as undeliverable; response rate $13.4 \%)^{3}$ and reported about 1990 different activity nodes. 363 respondents had fully completed the survey, of which 30 respondents reported having committed at least 1 crime in the year prior to the survey. ${ }^{4}$ In total, they reported on 71 unique crimes.

\section{Time-specific Activity Space (TAS) survey}

The survey first asked to report on daily and weekly routine activities, categorized in seven different domains: (1) residences, (2) schools, (3) jobs, (4) sports activities, (5) shopping, (6) going out, and (7) any other activities, for which respondents could specify the type of activity themselves. For each domain, the respondents were asked to indicate whether they had visited such an activity node about weekly over the past year. If so, they were asked for a maximum of six locations per domain to pinpoint the exact location using the Google Maps functionality included in the LimeSurvey platform to which we added an interactive search bar: three for current activity locations and three

\footnotetext{
${ }^{2}$ We explicitly stated that all the given answers of the respondents would be carefully stored on a secure server that only employees of the study could access and that we would never share the completed answers with any other party. In this way, our aim was to encourage respondents to report about any crime in the past year, both known and unknown to the police.

${ }^{3}$ Response rate as of September 2020. This response rate is comparable to the $12.4 \%$ response in the study of Menting et al. (2020) and the $18.3 \%$ response in the nationwide online transportation survey of Statistics Netherlands (Statistics Netherlands, 2016).

4 The offenders were selected in 2017 but asked about their offending in 2018-2019 (i.e. the year prior to the survey date). This lag was due to time delays in accessing police data and because we did not want to miss out on potential imprisoned respondents.
} 
for past activity locations (except for residences, as only one current home location could be reported and up to a maximum of five prior home locations in the past year). The pinpointed locations were automatically geocoded by storing the longitude-latitude information.

For each of these locations, respondents indicated during which days of the week and times of the day they had usually visited that location in the past year. For each day, we presented the respondents with eight possible time slots of three hours each (starting from midnight-3 am and ending at 9 pm-midnight). Respondents were also asked during which months of the previous year they had regularly visited that location.

In the second part of the survey, we asked respondents whether they had committed the following crime types in the past year: (1) residential burglary, (2) theft of/from a bicycle, car or other (motor) vehicle, (3) theft from a shop/shoplifting, (4) theft (of an object) from a person, (5) robbery, (6) assault, and (7) vandalism. For up to three incidents per crime type, we asked respondents to provide spatio-temporal details, similar to the spatial and temporal survey questions regarding their routine activities: the exact location on an interactive map of the Netherlands, and in which month of the year, day of the week and 3-h time slot the crimes were committed.

For each of the seven activity domains as well as for each reported crime type, respondents were asked to indicate the accuracy of their responses for the locations (i.e., whether their selection indicates a specific address, street, neighbourhood, or city), as well as the accuracy of the reported time slots of the day, days of the week and months of the year (i.e., very accurate, reasonably accurate, reasonably inaccurate, very inaccurate).

\section{Operationalization and method}

In order to determine the adequate spatial and temporal resolution for our unit of analysis, we first checked the reported level of accuracy for the seven routine activity domains and the five different reported types of crime. Spatial accuracy was generally higher for the reported routine activity nodes than for the crimes. However, for all 12 categories combined, more than three-quarters of the locations were indicated to be reported at least at the neighbourhood level. Therefore, we geocoded the longitude-latitude information to one of the 13,305 unique neighbourhoods in the Netherlands for the year 2018 , with a median area of $0.66 \mathrm{~km}^{2}$ (mean $=2.63$, range $=0.02-130.14$ ) (Statistics Netherlands 2019). To ensure that activity patterns preceded the crimes, we removed those activity nodes respondents only started visiting after the crime event. For more than $80 \%$ of the reported times in the survey, the respondents indicated the timing of their routine and criminal activities in the eight different 3-h time slots as "reasonably accurate" or "very accurate". The data show that our 3-h time slots offered respondents a more detailed temporal granularity than necessary: most locations are visited across a number of 3-h time slots. We therefore divided the time of day category into the two most distinct time blocks: daytime (6 am-6 pm) vs. nighttime (6 pm-6 am). ${ }^{5}$

The dependent variable crime committed in neighbourhood $(1=$ yes; $0=$ no) indicates whether or not an offence was committed in a specific neighbourhood. For each of the 71 crimes, the neighbourhood in which the offender had committed the offence was assigned a score of 1 , while all other 13,304 neighbourhoods were scored 0 . The independent variable neighbourhood routinely visited $(1=$ yes; $0=$ no) indicates whether or not a neighbourhood was part of the offenders' activity space in the period before or during the crime event. A score of 1 was assigned to all the neighbourhoods the offender routinely visited and all other neighbourhoods were scored 0 . In order to test our hypotheses, we combined the neighbourhood and timing information into two independent variables: neighbourhood routinely visited at same time of day as crime event $(1=$ yes; $0=$ no) and neighbourhood routinely visited at different time of day as crime event $(1=$ yes; $0=$ no). For example, when a certain neighbourhood was routinely visited by an offender during the night (i.e., inside the nighttime activity space of the offender) and the crime was committed during the day (or vice versa), the former variable scored 0 and the latter scored 1 . When a crime was committed during the day in a neighbourhood that was also part of the offender's daytime activity space (or both during the night), or when crime was committed in a neighbourhood that was both part of the offender's daytime and nighttime activity space, the former variable scored 1 and the latter $0 .{ }^{6}$

To provide a first empirical test of our extended crime pattern theory, we estimated a conditional logit model as commonly applied in crime location choice research (Bernasco and Ruiter 2014; Ruiter 2017). The choice outcome is the neighbourhood the offender selected for committing the offence. Because each of the 71 offences could have been committed in any of the 13,305 neighbourhoods

\footnotetext{
${ }^{5}$ Although the theoretical arguments made about differences between daytime and nighttime activity spaces (see "Extending crime pattern theory with time-varying applicability of spatial knowledge" paragraph) could also be applied to weekdays vs. weekends, we were not able to empirically test this hypothesis because there was too much overlap between the activities that took place on both weekdays and weekends (i.e. many locations were visited during both).

6 We also estimated a conditional logit model with three independent variables that also includes the variable neighbourhood routinely visited at both same and different time of day as crime event (see Table 3 in the Appendix), but the overall conclusions with regard to our hypotheses remained the same.
} 


\begin{tabular}{|c|c|c|c|}
\hline & No crime & Crime & Total \\
\hline \multicolumn{4}{|l|}{ Neighbourhood is ... } \\
\hline ... Outside of activity space & 944,332 & 43 & 944,375 \\
\hline ... Inside of activity space & 252 & 28 & 280 \\
\hline Total & 944,584 & 71 & 944,655 \\
\hline
\end{tabular}

of the Netherlands in 2018, the final dataset for analysis is a data matrix of 944,655 rows (containing 13,305 neighbourhood rows for each of the 71 crimes to be explained). Because the small sample size does not justify using normal standard errors, we calculated bootstrapped standard errors based on 100 samples. These were also cluster-corrected, because the 71 offences had been committed by 30 different offenders. The results of the conditional logit models are presented using odds ratios (ORs) and their respective bootstrapped cluster-corrected standard errors (SEs). As the independent variables score 0 when the offender had not routinely visited a certain neighbourhood before and therefore that neighbourhood is outside the activity space of the offender (i.e., the reference category), the effects of the study variables are expected to be positive with odds ratios greater than 1 .

\section{Results}

\section{Descriptive statistics}

We start this section with descriptive statistics of the offenders and their offences. Half (i.e. 15) of the 30 offenders reported having committed only a single offence in the year prior to the survey. Three offenders had committed two offences, nine offenders three offences, and the remaining three offenders had committed 4, 8, and 11 offences, respectively. Regarding the specific type of offences, the following frequencies were observed for the 71 offences in the dataset: two residential burglaries, nine thefts of/from a bicycle, car or other (motor) vehicle, 40 thefts from a shop/shoplifting, 14 assaults, and six acts of vandalism.

To investigate the extent to which offenders committed their offences inside their activity spaces, Table 1 presents a cross-tabulation of activity space by crime location $(N=71$ crimes * 13,305 possible neighbourhoods $=944,655)$. For each offence, there were several possibilities in each of the 13,305 Dutch neighbourhoods: a crime was either committed or not committed in that neighbourhood, and the neighbourhood was either inside or outside the activity space of the offender. Although the offenders could have committed their crimes in all of the 13,305 possible neighbourhoods of the Netherlands,

\begin{tabular}{|c|c|c|c|c|}
\hline & OR & SE & Z & $\mathbf{P}$ \\
\hline \multicolumn{5}{|l|}{ Neighbourhood routinely visited at ... } \\
\hline ... Same time of day as crime event & 2589.71 & 1365.30 & 14.91 & 0.001 \\
\hline $\begin{array}{l}\text {... Different time of day as crime } \\
\text { event }\end{array}$ & 1209.00 & 8703.08 & 0.99 & 0.324 \\
\hline Pseudo- $R^{2}$ & 0.27 & & & \\
\hline
\end{tabular}

$\mathrm{OR}=$ odds ratio coefficient and $\mathrm{SE}=$ bootstrapped cluster-corrected standard error

we observe that 28 out of the 71 crimes were committed in a neighbourhood that the offender routinely visited in the period before or during the crime event (median area $=0.36 \mathrm{~km}^{2}$ ). This means that $39.4 \%$ of the offences are committed within the neighbourhoods of offenders' own activity nodes.

We not only expect that neighbourhoods with routine activity nodes have a higher chance to be targeted, but also-to a lesser extent-neighbourhoods nearby, which offenders might visit less frequently or only traverse on their way to their activity nodes. If we include first-order spatial lags (i.e., neighbourhoods adjacent to those with the activity nodes), second-order spatial lags, and even thirdorder spatial lags, the median area of the neighbourhoods increased to $3.37 \mathrm{~km}^{2}, 14.5 \mathrm{~km}^{2}$, and $55.6 \mathrm{~km}^{2}$, respectively. We indeed find that the percentage of offences that were committed inside offenders' activity spaces rapidly increases from $59.2 \%$ (first-order spatial lags) to $70.4 \%$ (second-order lags), and 84.5\% (third-order lags).

\section{A first test of the extended theory}

The results of the conditional logit model that tests whether offenders are more likely to commit crime in neighbourhoods they have regularly visited at the same time of day than in neighbourhoods they have regularly visited at different parts of the day are displayed in Table 2. ${ }^{7}$ The results show that the odds ratio for our main study variable neighbourhood routinely visited at same time of day as crime event is positive and statistically significant $(p<0.001)$. This means that offenders are more likely to commit crime in neighbourhoods that were part of their time-specific activity space compared to neighbourhoods that were not. More specifically, the odds of committing crime in neighbourhoods that are routinely visited at the same time of day as the crime event is more than 2500

\footnotetext{
7 The conditional logit model uses the original neighbourhood areas instead of the lagged neighbourhoods.
} 
times that of committing crime in neighbourhoods not part of one's activity space. Moreover, we observe that this odds ratio ( $\mathrm{OR}=2589.71)$ is estimated to be considerably higher than the odds ratio for neighbourhood routinely visited at different time of day as crime event $(\mathrm{OR}=1209.00)$. A Wald Chi-Squared difference test on our small sample does not detect a statistically significant difference between the two odds ratios $\left(\chi^{2}(1)=0.01, p=0.915\right)$, but the difference is clearly in the expected direction. The odds ratio for neighbourhood routinely visited at different time of day as crime event also does not reach statistical significance $(p=0.324)$.

With only our two independent study variables, the pseudo- $\mathrm{R}^{2}$ of the model is 0.27 , which represents according to McFadden's guidance an excellent fit to the data (McFadden 1978, p. 307). The results suggest that offenders are more likely to commit crime in neighbourhoods they have regularly visited at the same time of day than in neighbourhoods they have regularly visited at different times of day, although the effect size difference was not statistically significant in our small sample-but clearly in the expected direction. This provides only tentative support for Hypothesis 1. In addition, offenders also appear to be more likely to commit crime in neighbourhoods they have regularly visited at different times of day than in neighbourhoods that are outside their activity space, but the odds ratio was not statistically significant. This also provides only tentative support for Hypothesis 2 .

\section{Discussion}

According to crime pattern theory, offenders commit crime at those places where their individual awareness spaces overlap with the spatial distribution of attractive targets. However, both the theory and the related empirical research have remained rather a-temporal, as if the timing of routine activities and crime plays no role. In the present study, we extended crime pattern theory and proposed that an offender's spatial knowledge acquired during daily routine activities is not equally applicable to all times of day. For a first empirical test of the extended theory, we collected detailed information about the spatio-temporal routine activity patterns and crime locations in a high-risk offender sample. The results showed that almost $40 \%$ of the offences (39.4\%) were committed within the neighbourhoods of offenders' activity nodes, increasing to $84.5 \%$ when including first-, second- and third-order spatial lags surrounding the activity node neighbourhoods. This corresponds with findings from the study of Menting et al. (2020), who reported 39.3\% and $88.6 \%$, respectively. This finding provides strong support for the original crime pattern theory (Brantingham et al. 2017; Brantingham and Brantingham 1981, 1993). Though not statistically significant, the results further suggest that offenders are more likely to commit crime in neighbourhoods they have regularly visited at the same time of day than in neighbourhoods they have regularly visited at different times of day. Our extension of crime pattern theory is therefore only tentatively supported.

Although this first empirical test provides some evidence for our extended theory, it is important to emphasise that our conclusions are tentative as the size of our sample of offences was quite small ( $N=71$ offences committed by 30 offenders). Also, a non-experimental research design obviously cannot fully rule out possible selection bias. As our respondents were sampled from police register data on suspected offenders from two specific police regions in the western part of the Netherlands (The Hague and Noord-Holland), we might not be able to generalize our findings to the broader offender population; to offenders in other parts of the country or to offenders that escaped arrest. The findings we observe might in part be related to the police being better able to solve offences that were committed inside the offenders' activity spaces. However, research using DNA-traces found at crime scenes suggests that the spatial patterns of solved and unsolved cases do not differ much (Lammers 2014).

As explained in more detail in the "Study design and sampling procedure" paragraph, the original suspect data from the police included relatively minor offences from offenders with relatively short offence histories. Compared to offenders with longer offence histories and more serious offences, this suspect group is found to have a decreased likelihood of continuing to commit crime in subsequent years (Lammers et al. 2012). We find some confirmation for this finding when we compare the percentage of respondents that reported undertaking a crime in our study $(8.3 \%)$ with the percentage found in the study of Menting et al. (2020) (18.9\%). Menting and colleagues used exactly the same research design, but a sample that was not restricted to suspects of minor crimes only. If the findings of our study would be related to the number and severity of offences, we should have found different spatial results than those presented by Menting et al. (2020), who analysed a sample that also included more persistent offenders who committed more severe offences. However, the results were actually quite comparable between the two studies.

Another common limitation of retrospective survey research is that the accuracy of recall from respondents' memory is uncertain. This would not be a problem if all respondents have equal memory loss, but respondents who had committed their crimes outside of their awareness space might have had more difficulty recollecting details about the crime locations and timings than respondents who had committed crime within their awareness space. However, we analysed crime locations at the neighbourhood level and dichotomized the timing of crime into daytime and nighttime crimes, which makes possible inaccuracy of recall less problematic. Besides, the respondents indicated that over 
three-quarters of the locations were reported at neighbourhood level or with higher accuracy, and in more than $80 \%$ of the reported times, the timing of their activities was reported reasonably or very accurately.

Notwithstanding these shortcomings, this study has presented an extended crime pattern theory to better explain not just where but also when crimes are committed. We argued that the applicability of the spatial knowledge offenders acquire during their daily routine activities needs to be conceptualized as time-varying, because it may not be applicable to all times of day. Although we presented the first tentative empirical evidence for the extended theory, we urge others to replicate our study with larger samples before any firm conclusions are warranted. Future studies with larger samples might benefit from using a similar design to map offenders' time-specific activity spaces, especially if also more serious offenders with longer offence histories are included. We believe that the use of our online survey instrument has a great advantage over previous registerbased studies, as we were able to study a much wider range of activity nodes than those usually included and we were able to capture the time of day offenders usually visited their activity nodes. Another way forward might be to use smartphone applications to track the whereabouts of people (see e.g., Ruiter and Bernasco 2018) or other type of GPS-tracking data (e.g., Rossmo et al. 2012). These methodologies can be used to even more comprehensively measure offenders' activity spaces, such as a wider range of routine activities as well as the routinely travelled paths between activity nodes.

When such new data get collected, it is worthwhile to assess whether the distinction between planned and opportunistic crimes can more explicitly be taken into account. For example, an opportunistic offender might seize some crime opportunity on the way to work and the timing of crime will then be around the start of the working day. For crimes that require more planning, we expect that the mechanism as proposed in our extended theory is at play: offenders acquire knowledge of their environment during ordinary daily routine activities that only at certain times is applicable for the commission of crime in other situations. However, this might also depend on the specific type of offence involved. We can imagine, for example, that bank robbers would go to some lengths to familiarize themselves with the area around the target bank before committing the offence, which may well be some way from their activity spaces. Although we did not measure the exact degree of planned and opportunistic behaviour for our offender group, our online questionnaire included a question about whether the offender was at the specific place and time of the crime in order to commit the crime or for some other reason. We observe that the percentage of planned offences that were committed inside and outside of the offenders' activity space were quite comparable $(25.6 \%$ and $32.1 \%$, respectively). In this regard, it would also be interesting to further distinguish between different types of crime. Unfortunately, our small sample size prohibits any further disaggregation.

To conclude, we introduced an extended crime pattern theory to understand both the spatial and temporal patterns in crime and we put it to a first empirical test. Although we found tentative support for our extended theory, it is for future studies with larger samples to replicate our research and shed more light on the specific mechanisms behind the theory.

\begin{abstract}
Acknowledgements
The authors would like to thank René Hesseling (The Hague Police) and Anne Mooij (North-Holland Police) of The Netherlands Police for providing suspect data from their respective police regions. The authors would also like to thank the three anonymous reviewers for their helpful feedback on the original version of the article.
\end{abstract}

Authors' contributions

All authors read and approved the final manuscript.

Funding

The research leading to this study has received funding from the Netherlands Organization for Scientific Research (NWO) under the Research Talent program (406-16-504 to S.v.S.).

Availability of data and materials

Data will not be shared, due to privacy reasons.

Competing interests

The authors declare that they have no competing interests.

Author details

${ }^{1}$ Department of Sociology, Utrecht University, Padualaan 14, 3584 CH Utrecht, The Netherlands. ${ }^{2}$ Netherlands Institute for the Study of Crime and Law Enforcement (NSCR), P. O. Box 71304, 1008 BH Amsterdam, The Netherlands.

Table 3 Conditional logit model testing the effects of time-varying activity spaces on crime location choice $(N=71$ crimes $* 13,305$ possible neighbourhoods $=944,655$ )

\begin{tabular}{|c|c|c|c|c|}
\hline & OR & SE & $\mathbf{Z}$ & $\mathbf{P}$ \\
\hline \multicolumn{5}{|l|}{ Neighbourhood routinely visited at ... } \\
\hline ... Both same and different time of day as crime event & 3145.23 & 2340.03 & 10.82 & 0.001 \\
\hline ... Only same time of day as crime event & 1966.20 & 942.02 & 15.83 & 0.001 \\
\hline ... Only different time of day as crime event & 1204.35 & 8108.26 & 1.05 & 0.292 \\
\hline Pseudo- $R^{2}$ & 0.27 & & & \\
\hline
\end{tabular}

$\mathrm{OR}=$ odds ratio coefficient and $\mathrm{SE}=$ bootstrapped cluster-corrected standard error 


\section{Appendix}

\section{See Table 3.}

Received: 11 August 2020 Accepted: 7 January 2021

Published online: 29 January 2021

\section{References}

Andresen, M. A., \& Malleson, N. (2013). Crime seasonality and its variations across space. Applied Geography, 43, 25-35. https://doi.org/10.1016/j. apgeog.2013.06.007.

Baudains, P., Braithwaite, A., \& Johnson, S. D. (2013). Target choice during extreme events: A discrete spatial choice model of the 2011 London riots. Criminology, 51, 251-285. https://doi.org/10.1111/1745-9125.12004.

Bernasco, W., Johnson, S. D., \& Ruiter, S. (2015). Learning where to offend: Effects of past on future burglary locations. Applied Geography, 60, 120-129. https:// doi.org/10.1016/j.apgeog.2015.03.014.

Bernasco, W., \& Kooistra, T. (2010). Effects of residential history on commercial robbers' crime location choices. European Journal of Criminology, 7(4), 251-265. https://doi.org/10.1177/1477370810363372.

Bernasco, W., \& Ruiter, S. (2014). Crime location choice. In G. Bruinsma \& D. Weisburd (Eds.), Encyclopedia of criminology and criminal justice (pp. 691-699). New York: Springer.

Blom, M., Oudhof, J., Bijl, R. V., \& Bakker, B. F. M. (2005). Verdacht van criminaliteit: Allochtonen en autochtonen nader bekeken [A closer look at persons of foreign and Dutch heritage]. Den Haag: WODC.

Bowers, K. J., \& Johnson, S. D. (2005). Domestic burglary repeats and space-time clusters: The dimensions of risk. European Journal of Criminology, 2(1), 67-92. https://doi.org/10.1177/1477370805048631.

Brantingham, P. L., \& Brantingham, P. J. (1981). Notes on the geometry of crime. In P. J. Brantingham \& P. L. Brantingham (Eds.), Environmental criminology (pp. 27-54). Beverly Hills: Sage.

Brantingham, P. L., \& Brantingham, P. J. (1993). Nodes, paths and edges: Considerations on the complexity of crime and the physical environment. Journal of Environmental Psychology, 13(1), 3-28.

Brantingham, P. J., Brantingham, P. L., \& Andresen, M. A. (2017). The geometry of crime and crime pattern theory. In R. Wortley \& M. Townsley (Eds.), Environmental criminology and crime analysis (Vol. 2). Abington: Routledge.

Ceccato, V. (2005). Homicide in Sao Paulo, Brazil: Assessing spatial-temporal and weather variations. Journal of Environmental Psychology, 25(3), 307-321.

Chainey, S., \& Ratcliffe, J. (2013). GIS and crime mapping. Hoboken: Wiley.

Cohen, L. E., \& Felson, M. (1979). Social change and crime rate trends: A routine activity approach. American Sociological Review, 44(4), 588-608. https://doi. org/10.2307/2094589.

Cromwell, P. F., Olson, J. N., \& Avary, D. A. W. (1991). Breaking and entering: An ethnographic analysis of burglary. Newbury Park: Sage Publications.

Curtis-Ham, S., Bernasco, W., Medvedev, O. N., \& Polaschek, D. (2020). A framework for estimating crime location choice based on awareness space. Crime Science. https://doi.org/10.1186/s40163-020-00132-7.

Eck, J., Chainey, S., Cameron, J., \& Wilson, R. (2005). Mapping crime: Understanding hotspots.

Farrell, G. Phillips, C., \& Pease, K. (1995). Like taking candy. Why does repeat victimization occur? British Journal of Criminology, 35(3), 384-399.

Johnson, S. D., Birks, D. J., McLaughlin, L., Bowers, K. J., \& Pease, K. (2007). Prospective crime mapping in operational context: Final report. London: Home Office.

Johnson, S. D., \& Summers, L. (2015). Testing ecological theories of offender spatial decision making using a discrete choice model. Crime \& Delinquency, 1, 27. https://doi.org/10.1177/0011128714540276.
Lammers, M. (2014). Are arrested and non-arrested serial offenders different? A test of spatial offending patterns using DNA found at crime scenes. Journal of Research in Crime and Delinquency, 51(2), 143-167. https://doi. org/10.1177/0022427813504097.

Lammers, M., Bernasco, W., \& Elffers, H. (2012). How long do offenders escape arrest? Using DNA traces to analyse when serial offenders are caught. Journal of Investigative Psychology and Offender Profiling, 9(1), 13-29.

Linning, S. J., Andresen, M. A., \& Brantingham, P. J. (2017). Crime seasonality: Examining the temporal fluctuations of property crime in cities with varying climates. International Journal of Offender Therapy and Comparative Criminology, 61(16), 1866-1891.

McFadden, D. (1978). Quantitative methods for analyzing travel behaviour of individuals: some recent developments. In D. A. Hensher \& P. R. Stopher (Eds.), Behavioural travel modeling (pp. 279-318). Kent: Croom Helm.

Menting, B. (2018). Awareness $x$ opportunity: testing interactions between activity nodes and criminal opportunity in predicting crime location choice. The British Journal of Criminology, 58(5), 1171-1192. https://doi.org/10.1093/ bjc/azx049.

Menting, B., Lammers, M., Ruiter, S., \& Bernasco, W. (2020). The influence of activity space and visiting frequency on crime location choice: findings from an online self-report survey. The British Journal of Criminology, 60(2), 303-322. https://doi.org/10.1093/bjc/azz044.

Morgan, F. (2001). Repeat burglary in a Perth suburb: Indicator of short-term or long-term risk? Crime Prevention Studies, 12, 83-118.

Rengert, G. F., \& Wasilchick, J. (2000). Suburban burglary: A tale of two suburbs. Springfield: Charles $C$. Thomas.

Rossmo, D. K., Lu, Y., \& Fang, T. B. (2012). Spatial-temporal crime paths. In M. A. Andresen \& J. B. Kinney (Eds.), Patterns, prevention, and geometry of crime (pp. 38-64). Abington: Routledge.

Rossmo, D. K., Lutermann, H., Stevenson, M. D., \& Le Comber, S. C. (2014). Geographic profiling in Nazi Berlin: Fact and fiction. Geospatial Intelligence Review.

Ruiter, S. (2017). Crime location choice: State-of-the-art and avenues for future research. In W. Bernasco, H. Elffers, \& J.-L. Van Gelder (Eds.), The Oxford handbook on offender decision making (pp. 398-420). Oxford: Oxford University Press.

Ruiter, S., \& Bernasco, W. (2018). Is travel actually risky? A study of situational causes of victimization. Crime Science. https://doi.org/10.1186/s4016 3-018-0084-6

Sherman, L. W., Gartin, P. R., \& Buerger, M. E. (1989). Hot spots of predatory crime: Routine activities and the criminology of place. Criminology, 27(1), 27-56.

Statistics Netherlands. (2016). Onderzoek Verplaatsingen in Nederland (OViN) 2016. The Hagure: Statistics Netherlands.

Statistics Netherlands. (2019). Toelichting Wijk-en Buurtkaart 2017, 2018 en 2019. The Hague: Statistics Netherlands.

Van Sleeuwen, S. E. M., Ruiter, S., \& Menting, B. (2018). A time for a crime: Temporal aspects of repeat offenders' crime location choices. Journal of Research in Crime and Delinquency, 55(4), 538-568. https://doi.org/10.1177/0022427818 766395.

Wiles, P., \& Costello, A. (2000). The "road to nowhere": The evidence for travelling criminals. London: Home Office Research Study No. 207, Development and Statistics Directorate.

Wortley, R., \& Townsley, M. (2017). Environmental criminology and crime analysis: Situating the theory, analytic approach and application. In R. Wortley \& M. Townsley (Eds.), Environmental criminology and crime analysis. London: Routledge.

\section{Publisher's Note}

Springer Nature remains neutral with regard to jurisdictional claims in published maps and institutional affiliations. 